\title{
КНИГОВЕДЕНИЕ. БИБЛИОГРАФОВЕДЕНИЕ
}

УДК 002.2+01

DOI: $10.33186 / 1027-3689-2021-9-115-128$

\author{
В. П. Леонов \\ Библиотека РАН, Санкт-Петербург, Российская Федерация
}

\section{Новые горизонты науки о книге и библиографии}

Аннотация: В отличие от наук, которые формировались постепенно и во многом стихийно, развитие книговедческих дисциплин строилось на их теоретическом осмыслении без ожидания, что все они возникнут естественным путём. Невыясненным остаётся центральный вопрос: являются ли книговедение и его производные - библиотековедение, библиографоведение - комплексом научных дисциплин или комплексной дисциплиной? Цель настоящей статьи - рассмотреть теоретические вопросы о книге и библиографии как о свойствах живых систем: каково их предназначение, как они «работают» в организме, как возникают в ходе эволюции и как себя проявляют? Опираясь на достижения нейронауки, прежде всего на исследования академика РАН К. В. Анохина и его коллег, автор рассматривает книгу как внешний когнитом. Она представляет собой полную, отчуждённую систему субъективного опыта, сформированного у организма в процессе эволюции, индивидуального развития и обучения. Другими словами, книга в нас уже есть, она уже «заложена» в организме. Автор книги не должен её изобретать, он должен её «перевести». Библиографию по этой логике можно рассматривать как надстройку над внешним когнитомом. Это сеть над сетью - гиперсеть. Главным вопросом общей теории является понимание механизма взаимодействия трёх элементов: книги (К) и (И) библиографии (Б) - КИБ, где И - ключевой элемент. В статье рассмотрены вопросы чтения как вызова для мозга и мышления в цифровую эпоху. Особое внимание уделено «дальнему чтению» (Ф. Моретти) с использованием Digital Humanities - цифровых методов в гуманитарных науках. Отмечено, что предшественником Ф. Моретти был российский исследователь Б. И. Ярхо (18891942). В заключение сделан вывод: общая теория науки о книге и библиографии должна базироваться на трёх составляющих: 1) понимании механизма взаимосвязи книги как внешнего когнитома и библиографии как гипертекста (КИБ); 2) изучении взаимодействия пристального и дальнего чтения в цифровую эпоху; 3) формировании основ теории точного библиографоведения. 
Статья подготовлена на основе доклада, представленного в ходе Второй научно-практической конференции «Буква и Цифра: библиотеки на пути к цифровизации» («БиблиоПитер-2021»), Санкт-Петербург, 21 апреля 2021 г.

Ключевые слова: К. В. Анохин, когнитом, книга как внешний когнитом, библиография как гиперсеть, Франко Моретти, дальнее чтение, точное библиографоведение. 


\title{
BIBLIOLOGY. BIBLIOGRAPHY SCIENCE
}

UDC 002.2+01

DOI: $10.33186 / 1027-3689-2021-9-115-128$

\author{
Valery P. Leonov \\ Russian Academy of Sciences Library, St. Petersburg, Russian Federation
}

\section{New horizons of book science and bibliography}

\begin{abstract}
In contrast to the sciences, that were formed gradually and in many ways spontaneously, the development of bibliological disciplines was based on their theoretical comprehension without the expectation that they would all arise naturally. The central question remains unclear: is bibliology and its derivatives (library science, bibliography science) a complex of scientific disciplines or a complex discipline? In most cases, their union is limited to separate concepts that unite an established range of problems. This article aims to consider theoretical questions about the book and the bibliography as properties of living systems: what is their purpose, how do they "work" in the body, how do they arise in the course of evolution and how do they behave? Based on the achievements of neuroscience, first of all, on the research of Academician of the Russian Academy of Sciences K. V. Anokhin and his colleagues, the author considers the book as an external cognitome. It is a complete, alienated system of subjective experience formed in an organism in the process of evolution, individual development and learning. In other words, the book is already in us, it is already "embedded" in the body. The author must not invent it, he must translate it. Therefore bibliography can be viewed as a superstructure over an external cognitome. This is a network over a network, i. e. a hypernet. The main general theory is the understanding of the mechanism of interaction of three elements: books (kniga in Russian - K) and (in Russian - I) a bibliography (bibliografiya in Russian - B) - these stands for KIB, where I (and) is the key element. The article considers the issues of reading as a challenge for the brain and thinking in the digital age. Particular attention is paid to "distant reading" (F. Moretti) by using Digital Humanities. F. Moretti's predecessor was the Russian researcher B. I. Yarkho (1889-1942). It concludes that the general theory of science about a book and bibliography should be based on three components: 1) understanding the mechanism of the relationship between a book as an external cognitome and bibliography as a hypertext (KIB); 2) exploring the study of close and distant reading in the digital age; 3 ) the formation of the foundations of the theory exact study of bibliography.
\end{abstract}

Keywords: K. V. Anokhin, cognitome, book as an external cognitome, bibliography as hypernet, Franco Moretti, distant reading, exact study of bibliography. 
Изучая историю науки, мы замечаем два явления, которые можно назвать взаимно противоположными: то за кажущейся сложностью скрывается простота, то, напротив, видимая простота на самом деле таит в себе чрезвычайную сложность.

Анри Пуанкаре [1. С. 121]

Как известно, книга и библиография лежат в основе двух научных направлений - книговедения и библиографоведения. Обо всех этих дефинициях на сегодня уже достаточно много и сказано, и написано, и обосновано. Однако вопрос о построении их общей теории остаётся открытым. Для его решения, как мне представляется, есть два магистральных пути: либо продолжать изучать их прошлое развитие, либо устремиться в будущее. Я выбираю последнее, так как это, прежде всего, собственное развитие каждого направления, которое определяется совокупностью междисциплинарных связей.

И книговедение, и библиографоведение благодаря междисциплинарным связям обогащаются достижениями других наук, а они, в свою очередь, дополняют их новым знанием. В частности, развитие книговедческих наук зависит от состояния и результатов в социологии, биологии, психологии, педагогике, информатике. И наоборот, ни одна из перечисленных научных отраслей не сможет успешно развиваться, если не будет ориентироваться на достижения в области книги и библиографии. Сегодня среди книговедов и библиографоведов наблюдается стремление пересмотреть устоявшиеся базовые понятия, представления и найти новый взгляд на привычные суждения. Объективно это правильно, поскольку новое, безусловно, рождается в процессе поиска, а не механического перенесения чужого опыта.

В отличие от наук, которые формировались постепенно и во многом стихийно (например, биология или языкознание), развитие книговедческих дисциплин строилось на их теоретическом осмыслении без ожидания, что все они возникнут «естественным» путём. Однако невыясненным по-прежнему остаётся центральный вопрос: являются ли книговедение и его производные - библиотековедение, библиографоведение - комплексом научных дисциплин или комплексной дисци- 
плиной? Если принять вторую точку зрения, которую я разделяю, возникает другой вопрос: что такое книга как объект комплексной дисциплины и какова в данном случае программа её исследования?

Несмотря на то что интерес к книге не ослабевает, о чём ежегодно свидетельствует множество публикаций, и учёные не испытывают недостатка в установленных фактах, не хватает единого теоретического обобщения, которое позволило бы связать эти факты. В большинстве случаев их союз ограничивается отдельными концепциями, объединяющими небольшой, но устоявщийся круг проблем.

Какие задачи возникают перед проектом новой общей теории? Мне представляется, что прежде всего она должна отвечать на вопросы о книге и библиографии как о свойствах живых систем: каково их предназначение, как они «работают» в организме, как возникают в ходе биологической эволюции и как себя проявляют? В теоретических размышлениях целесообразно, с одной стороны, опираться на факты нейронауки (например, на исследования академика РАН К. В. Анохина и его коллег), а с другой - истолковать и/или исчислить данные субъективного опыта [2, 3].

Обратимся к оригинальным рассуждениям К. В. Анохина $[4,5]$. Биологическая эволюция не поспевает за тем, что возникает за счёт культурного наследования. Это всегда сотни и тысячи лет. Эволюция не задаётся вопросом «зачем?». Она всегда движется вперёд, так же как и научное познание. Основная идея метафоры «Вавилонская библиотека», считает К. В.Анохин, - безграничность. Это что-то, что хранится. Наш разум может создать такое количество миров в себе, которое нельзя сосчитать. Это - бесконечность. Разум несёт какую-то идею, которую нужно объяснить. Это всё, что накоплено нашим опытом. А наш субъективный опыт есть продукт нервных клеток.

Разум - некая надстройка над физической материей мозга. Мозг это огромная сеть. Она очень похожа на сеть огней в большом городе или сеть интернета, или социальную сеть. Теория должна объяснить, как в эволюции появился разум, т. е. сеть, в которой элементами являются элементы нашего субъективного опыта? Другими словами, как появилась сеть над сетью, гиперсеть? Гиперсеть - это и есть наше «я», наша «Вавилонская библиотека», в которой уже записан текст. 
Каждая такая сеть или одно содержащееся в памяти «произведение» нашего мозга, нашего сознания - это когнитивный элемент. Имя ему - ког (Cognitive Group - COG). Комбинируя коги, можно воссоздать произведения Вавилонской библиотеки. В совокупности коги образуют систему опыта конкретного организма, которая называется когнитом [6].

Когнитивные процессы могут протекать только внутри когнитивных систем. Если мы хотим понять сознание, мы должны начать с изучения структур, в которых протекают эти процессы, заключает К. В. Анохин.

Итак, если когнитом - материя сознания (структура, в которой протекают физиологические процессы, в том числе и сознание), то книга, в концепции К. В. Анохина, - это внешний когнитом. Она представляет собой полную отчуждённую систему субъективного опыта, сформированного у организма в процессе эволюции, индивидуального развития и обучения [7].

Другими словами, книга в нас уже есть, она уже «заложена» в организме. Автор (писатель) не должен её изобретать, он должен её лишь перевести. Создание такого текста есть предмет перевода. Мне думается, этот подход - новый, неожиданный, но очень интересный.

Процесс чтения представляет собой заполнение разрыва между внешним когнитомом (книгой) и субъективным опытом читателя. Библиографию по этой логике можно рассматривать как надстройку над внешним когнитомом. Это сеть над сетью - гиперсеть. Центральная проблема предлагаемой общей теории: станет ли когнитом «золотым ключиком» к разгадке тайны книги и библиографии?

Обратимся теперь к нашей теме. Выделим три проблемы, которые входят в поле зрения теории когнитивных систем и знание которых необходимо книговеду и библиографу: 1) что такое книга как внешний когнитом? 2) что такое библиография как гипертекст внешнего когнитома? 3) как они соотносятся между собой?

Главным вопросом общей теории является понимание механизма организации взаимодействия трёх элементов: книги (К) и (И) библиографии (Б) - КИБа, где И - ключевой элемент, отвечающий за её реализацию. Имеется в виду понимание процессов: 1) как должна быть организована работа нервных клеток когнитома, чтобы в процессе эволюции появилась книга? 2) как должна быть организована книга, 
чтобы стать объектом библиографии? 3) как возникает союз КИБ? Для этого нужно понять элемент И...

Понимание - абсолютно личный акт. Знание может появиться только как личный акт понимания. Понимание И начинается с пристального чтения, известного под названием close reading. Но и с пристальным чтением всё не так просто, как кажется на первый взгляд. И в триаде КИБ - это заполнение разрыва между внешним когнитомом (книгой) и субъективным опытом (читателем).

Чтение текста - самая сложная задача для мозга человека, самый сложный вызов по сравнению с другими способами подачи информации (аудио, видео и др.). Почему? Потому что в процессе чтения мы должны преобразовать буквенные символы в слова и только потом в образы и смыслы. Это двойная задача, ибо, когда мы слышим речь или видим картинку, мы делаем только «шаг» в сторону мозга.

Сила читателя состоит в том, что он может «оживить» элемент И в КИБе. Благодаря чтению как вызову для мозга и мышления создаётся возможность проникнуть в умы других людей. Рассказанные истории, мысли других людей делают нашу жизнь богаче. Вместе с тем глубокое, медленное и пристальное чтение, как считает А. Мангуэль, директор Национальной библиотеки Аргентины, довольно опасно. Почему опасно? Потому что оно не столько отвечает на вопросы читателей, сколько задаёт их. С этим трудно не согласиться, неслучайно любая власть боится читателей, боится тех, кто читает глубоко и пристально. Интересным представляется факт, что с XVI в. (100 лет спустя после И. Гутенберга) все идеи революций принадлежали людям, увлечённым чтением $[8,9]$.

На современном этапе, который характеризуется наступательным и масштабным продвижением компьютерных технологий, многочисленные библиотеки и учебные центры мира повсеместно создают свои обширные базы литературных и библиографических текстов. Перед такими базами использование методов пристального чтения (close reading), рассчитанных на работу с конкретными источниками, казалось бы, теряет смысл. 
Ситуация не изменилась, а «перевернулась», сложное теперь лишнее, от него пытаются избавиться. Повсеместная цифровизация приводит к трансформации мышления, изменениям социально-культурных установок. Культура не умирает - она движется в новом направлении. Это новая сфера деятельности современного общества, будущее междисциплинарного исследования.

Объект цифровой информации и электронных услуг во всех сферах жизни людей привёл к такому проникновению интернета в профессиональную и повседневную жизнь людей, что он трактуется уже не как средство или инструмент, а как продолжение или расширение разума, познания и деятельности.

Формируется новая концепция инфосферы, где нет чётких границ [10]. Осуществляется интеграция интернет-устройств в «когнитивную архитектуру» человека, включая воздействие на развитие человека, его мозга и когнитивные способности. Электронная культура меняет человека, который, в свою очередь, эволюционирует таким образом, чтобы изменить культуру. Характерный пример - возникновение и развитие книгопечатания. Оно стало мощным импульсом развития человека и культуры, способствовало снижению социальных дистанций через обучение грамотности $[11,12]$.

Вернёмся к пристальному чтению. Как уже отмечалось, сегодня качество чтения меняется, и в этом смысле чтение - вызов для мозга, мышления [13]. Нам всё труднее усваивать длинные тексты, аргументированные статьи, а значит, труднее самим делать выводы. Мышление меняется, чтение движется в неизведанном направлении. И дело даже не в содержании книги, а скорее в возможностях чтения, которые она предоставляет.

Цифровая эпоха диктует новый стиль восприятия информации. В интернете мы используем поверхностное чтение (чтение по диагонали), поскольку объём информации оказывается настолько велик, что теряет часть своей ценности. Вместе с тем бумажной книге и пристальному чтению ничего не грозит в глобальном смысле. До тех пор, пока книги есть в семьях, школах, магазинах, библиотеках; до тех пор, пока они нас окружают... 
Главным критиком close reading стал итальянский социолог и литературовед Франко Моретти (род. 1950 г.). Свои идеи он изложил в книге «Дальнее чтение» («Distant reading») [14]. Эту книгу можно рассматривать как программу по обновлению методологии изучения мировой литературы. Моретти считает, что мировую литературу следует изучать не вглядыванием в детали при чтении конкретного текста, а путём рассмотрения её с большого расстояния: изучения сотен и тысяч текстов. Для такого чтения он предлагает использовать методологию $\mathrm{DH}$ Digital Humanities (цифровые методы в гуманитарных науках).

Заметим, что направление $D H$ уже завоевало своё место в гуманитарных междисциплинарных исследованиях. Главным аспектом междисциплинарности является сотрудничество специалистов разных гуманитарных и технических дисциплин. Помимо историков, филологов и специалистов в сфере информационных технологий, в $D H$ принимают участие библиотекари, библиографы, архивисты, профессионалы в области музейного дела.

В сообществе DH выделяют две группы специалистов: 1) исследователи как собиратели «фактов» в обширных электронных коллекциях; 2) исследователи как аналитики по изучению влияния цифровой среды на гуманитарные науки в целом $[15,16]$.

Большие массивы данных требуют новых подходов для дальнего чтения, анализа и их долгосрочного хранения. По этой причине главным вопросом развития $D H$ становится возможность аналитического использования цифрового потенциала гуманитарных сведений.

Что предлагает Ф. Моретти? Например, с помощью $D H$ определять частотность слов, подсчитывать количество диалогов между персонажами. Используя статистические методы, Моретти показывает закономерность изменения заглавий романов. Его интересуют глобальные вопросы, на которые нельзя ответить, ограничившись малым кругом авторов и текстов: почему возникает литература, какие принципы положены в её развитие? Чтобы показать причины выживаемости одних текстов, он сравнивает литературные процессы с биологическими и проводит аналогию естественного отбора с читательским.

Замечу, что предшественником Моретти был российский исследователь Борис Исаакович Ярхо (1889-1942) - автор фундаментальной монографии «Методология точного литературоведения» [3]. Именно 
Б. И. Ярхо первым использовал количественные методы в литературоведении и увидел общее между литературными и биологическими процессами.

Опираясь на дальнее чтение, Ф. Морети предлагает новый подход к традиционному вопросу литературоведения о том, каким образом единичные факты чтения могут быть обобщены в рамках литературной истории? Другими словами, концептуальные решения об использовании новых технологий в гуманитарных науках определяются концепциями гуманитарных наук. Такой подход открывает новый путь в истолковании и использовании количественных методов и для изучения мировой библиографии.

В качестве успешной попытки применить статистические методы дальнего чтения (Ф. Моретти) для анализа заглавий книг можно назвать исследование аспиранта Высшей школы печати и медиаиндустрии Московского политехнического университета Е. А. Тутатиной [17]. Суть её эксперимента состояла в следующем. Из отобранных 5 165 заглавий была составлена библиографическая база, включающая название книги, имя автора, год издания и жанр (роман, рассказ, повесть). Книги распределялись по направлениям: детектив, сентиментальная проза, фэнтези. Проверке подвергались издания, которые за последние

20 лет входили в списки бестселлеров газеты «The New York Times» (за исключением произведений А. Кристи и А. Конан Дойла).

Гипотеза исследования заключалась в том, что заглавия бестселлеров формируют «моду» на заглавия в издательском процессе. Как только книга становится бестселлером, её переводят на множество языков, появляются экранизации, и тогда заглавие начинают активно копировать. Результаты анализа представлены в виде таблиц и содержат интересную информацию для использования в издательской деятельности, т. е. позволяют понять, как заглавие влияет на популярность книги, какие заглавия являются модными и какие могут возникать при этом ошибки [17].

Итак, мне представляется, что общая теория науки о книге и библиографии должна базироваться, по крайней мере, на трёх составляющих: 
понимании механизма взаимосвязи книги как внешнего когнитома и библиографии как гипертекста (КИБ);

изучении взаимодействия пристального и дальнего чтения в цифровую эпоху;

формировании основ теории точного библиографоведения [18].

В заключение, обращаясь к эпиграфу этой статьи, приведу ключевые тезисы из выступления Анри Пуанкаре (1854-1912) «Гипотезы в физике» на Международном конгрессе физиков (Париж, 1900 г.). Они не потеряли своей актуальности и сегодня:

«...без обобщения невозможно и предвидение»;

«Лучше предвидеть без абсолютной уверенности, чем не предвидеть вовсе»;

«Задача состоит в том, чтобы повысить производительность научного познания» [1. С. 118, 119].

\section{СПИСок ИСточников}

1. Пуанкаре А. Наука и гипотеза / А. Пуанкаре // Пуанкаре А. О науке / пер. с фр. 2-е изд. - Москва : Наука, 1990. - С. 118-119. - 735 с.

2. Соколова Е. В. Истолковать и/или исчислить: о возможности комбинированного метода на стыке герменевтики и digitalhumanities / Е. В. Соколова // Соврем. наука о лит. : сб. ст. / РАН. ИНИОН. - Москва, 2018. - С. 142-155.

3. Ярхо Б. И. Методология точного литературоведения: Избранные труды по теории литературы / Б. И. Ярхо. - Москва : Языки славянской культуры, 2006. - XXXI, 926 с.

4. Анохин К. В. Мозг, сознание, интеллект (проект «когнитома») / К. В. Анохин // Александр Зиновьев и актуальные проблемы логики и методологии : докл. участников Логического семинара «Сохранение и приумножение науч. (логико-философ.) наследия А. А. Зиновьева». - Москва, 2017. - С. 230-235.

5. Анохин К. В. Наш разум - это гиперсеть / К. В. Анохин // Омилия : междунар. литератур. клуб. - URL: http://omiliya.org/node/21605 (дата обращения: 30.04.2021).

6. Чумаков В. Коды Вавилонской библиотеки мозга. Интервью с чл.-корр. РАН К. В. Анохиным / В. Чумаков // В мире науки. - 2013. - № 5. - С. 83-89.

7. Леонов В. П. Вавилонская библиотека в контексте дальнего чтения / В. П. Леонов // Библиогр. и книговедение. - 2020. - № 1. - С. 77-83. 
8. Мангуэль А. История чтения / А. Мангуэль. - Екатеринбург : У-Фактория, 2008. $381 \mathrm{c}$.

9. Мангуэль А. «Любая власть боится читателей» / А. Мангуэль // Горький Медиа. URL: https://gorky.media/context/lyubaya-vlast-boitsya-chitatelej/ (дата обращения: 30.04.2021).

10. Ефременко Д. В. Библиотеки на этапе перехода из «галактики Гутенберга» в «галактику Интернет» : аналит. обзор / Д. В. Ефременко, А. Ю. Долгов // Философия науки и техники. - 2020. - Т. 25. - № 1. - С. 65-80.

11. Касавина Н. А. Цифровизация как предмет междисциплинарных исследований / Н. А. Касавина // Эпистемология и философия науки. - 2019. - Т. 56, № 4. - С. 251-259.

12. Касавина Н. А. Человек и техника: амбивалентность электронной культуры / Н. А. Касавина // Там же. - 2018. - Т. 55. - № 4. - С. 129-142.

13. Мелентьева Ю. П. Общая теория чтения / Ю. П. Мелентьева. - Москва : Наука, 2015. - 230 c.

14. Моретти Ф. Дальнее чтение / Ф. Моретти ; пер. с англ. А. Вдовина, О. Собчука, А. Шели. - Москва : Изд-во Ин-та Гайдара, 2016. - 342 с.

15. Володин А. Ю. Digital Humanities (цифровые гуманитарные науки): в поисках самоопределения / А. Ю. Володин // Вестн. Перм. ун-та. Сер.: История. - 2014. Вып. 3 (26). - С. 5-12.

16. Таллер М. Дискуссии вокруг Digital Humanities / М. Таллер // Истор. информатика. - 2012. - № 1. - С. 5-13.

17. Тутатина Е. А. Заглавия книг: современные тенденции в книгоиздании / Е. А. Тутатина // Библиогр. и книговедение. - 2020. - № 1. - С. 111-119.

18. Леонов В.П. Дальнее чтение как стратегия точного библиографоведения / В. П. Леонов // Науч. и техн. б-ки. - 2019. - № 10. - С. 56-67.

\section{REFERENCES}

1. Puankare A. Nauka i gipoteza / A. Puankare // Puankare A. O nauke / per. s fr. 2-e izd. - Moskva : Nauka, 1990. - S. 118-119. - 735 s.

2. Sokolova E. V. Istolkovat i/ili ischislit: o vozmozhnosti kombinirovannogo metoda na styke germenevtiki i digitalhumanities / E. V. Sokolova // Sovrem. nauka o lit. : sb. st. / RAN. INION. - Moskva, 2018. - S. 142-155.

3. Yarho B. I. Metodologiya tochnogo literaturovedeniya: Izbrannye trudy po teorii literatury / B. I. Yarho. - Moskva : Yazyki slavyanskoy kultury, 2006. - XXXI, 926 s. 
4. Anohin K. V. Mozg, soznanie, intellekt (proekt «kognitoma») / K. V. Anohin // Alexander Zinovev i aktualnye problemy logiki i metodologii : dokl. uchastneykov Logicheskogo seminara "Sohranenie i priumnozhenie nauch. (logiko-filosof.) naslediya A. A. Zinoveva». Moskva, 2017. - S. 230-235.

5. Anohin K. V. Nash razum - eto giperset / K. V. Anohin // Omiliya : mezhdunar. literatur. klub. - URL: http://omiliya.org/node/21605 (data obrashcheniya: 30.04.2021).

6. Chumakov V. Kody Vavilonskoy biblioteki mozga. Intervyu s chl.-korr. RAN K. V. Anohinym / V. Chumakov // V mire nauki. - 2013. - № 5. - S. 83-89.

7. Leonov V. P. Vavilonskaya biblioteka v kontekste dalnego chteniya / V. P. Leonov // Bibliogr. i knigovedenie. - 2020. - № 1. - S. 77-83.

8. Manguel A. Istoriya chteniya / A. Manguel. - Ekaterinburg : U-Faktoriya, 2008. $381 \mathrm{~s}$

9. Manguel A. «Lyubaya vlast boitsya chitateley» / A. Manguel // Gorkiy Media. - URL: https://gorky.media/context/lyubaya-vlast-boitsya-chitatelej/ (data obrashcheniya: 30.04.2021).

10. Efremenko D. V. Biblioteki na etape perehoda iz «galaktiki Gutenberga» v «galaktiku Internet» : analit. obzor / D. V. Efremenko, A. Yu. Dolgov // Filosofiya nauki i tehniki. 2020. - T. 25. - № 1. - S. 65-80.

11. Kasavina N. A. Tsifrovizatsiya kak predmet mezhdistsiplinarnyh issledovaniy / N. A. Kasavina // Epistemologiya i filosofiya nauki. - 2019. - T. 56, № 4. - S. 251-259.

12. Kasavina N. A. Chelovek i tehnika: ambivalentnost elektronnoy kultury / N. A. Kasavina // Tam zhe. - 2018. - T. 55. - № 4. - S. 129-142.

13. Melenteva Yu. P. Obshchaya teoriya chteniya / Yu. P. Melenteva. - Moskva : Nauka, 2015. - $230 \mathrm{~s}$.

14. Moretti F. Dalnee chtenie / F. Moretti ; per. s angl. A. Vdovina, O. Sobchuka, A. Sheli. - Moskva : Izd-vo In-ta Guydara, 2016. - 342 s.

15. Volodin A. Yu. Digital Humanities (tsifrovye gumanitarnye nauki): v poiskah samoopredeleniya / A. Yu. Volodin // Vestn. Perm. un-ta. Ser.: Istoriya. - 2014. - Vyp. 3 (26). S. 5-12.

16. Taller M. Diskussii vokrug Digital Humanities / M. Taller // Istor. informatika. 2012. - № 1. - S. 5-13.

17. Tutatina E. A. Zaglaviya knig: sovremennye tendentsii v knigoizdanii / E. A. Tutatina // Bibliogr. i knigovedenie. - 2020. - № 1. - S. 111-119.

18. Leonov V. P. Dalnee chtenie kak strategiya tochnogo bibliografovedeniya / V. P. Leonov // Nauch. i tehn. b-ki. - 2019. - № 10. - S. 56-67. 
Информация об авторе / Information about the author

$\begin{array}{ll}\text { Леонов Валерий Павлович - доктор } & \text { Valery P. Leonov - Dr. Sc. (Peda- } \\ \text { пед. наук, профессор, научный ру- } & \text { gogy), Professor, Director of Re- } \\ \text { ководитель Библиотеки РАН, заслу- } & \text { search, Russian Academy of Sciences } \\ \text { женный работник культуры, Санкт- } & \text { Library, St. Petersburg, Russian Fede- } \\ \text { Петербург, Российская Федерация } & \text { ration } \\ \text { valleo@mail.ru } & \text { valleo@mail.ru }\end{array}$

